may have to wait several years to find whether discovering more cancers early means more lives saved.

\section{Competing interests None.}

Provenance and peer review Commissioned; internally peer reviewed.

Published Online First 14 February 2012

Thorax 2012;67:283-285

doi:10.1136/thoraxjnl-2011-201541

\section{REFERENCES}

1. Saghir Z, Dirksen A, Ashraf H, et al. CT screening for lung cancer brings forward early disease. The randomised Danish lung Cancer Screening Trial (DLSCT): status after five annual screening rounds with low-dose CT. Thorax 2012;67:296-301.

2. Infante M, Lutman FR, Cavuto $\mathrm{S}$, et al. Lung cancer screening with spiral CT: baseline results from the randomised DANTE trial. Lung Cancer 2008:59:355-63.

3. Blanchon T, Brechot JM, Grenier PA, et al. Baseline results from the Depiscan study: a French randomised pilot trial of lung cancer screening comparing low dose CT scan (LDCT) and chest x-ray (CXR). Lung Cancer 2007;58:50-8.

4. Van lersel CA, de Koning HJ, Draisma G, et al. Riskbased selection from the general population in a screening trial: selection criteria, recruitment and power for the Dutch-Belgian randomised lung cancer multi-slice CT screening trial (NELSON). Int J Cancer 2007; 120:868-74.

5. Lopes PA, Picozzi G, Mascalchi M, et al. Design, recruitment and baseline results of the ITALUNG tria for lung cancer screening with low-dose CT. Lung Cancer 2009;64:34-40.

6. Baldwin DR, Duffy SW, Wald NJ, et al. UK Lung Screen (UKLS) nodule management protocol: modelling of a single screen randomised controlled trial of low-dose CT screening for lung cancer. Thorax 2011;66:308-13.

7. Van Klaveren RJ, Oudkirk M, Prokop M, et al. Management of lung nodules detected by volume CT scanning. N Engl J Med 2009:361:2221-9.

8. Aberle DR, Adams AM, Berg CD, et al. Reduced lung cancer mortality with low-dose computed tomographic screening. N Engl J Med 2011;365:395-409.
9. McMahon PM, Kong CY, Bouzan B, et al. Costeffectiveness of computed tomography screening for lung cancer in the United States. J Thorac Oncol 2011;6:1841-8.

10. Evans WK, Wolfson MC. Computed tomography screening for lung cancer without a smoking cessation program - not a cost-effective idea. J Thorac Oncol 2011:6:1781-3.

11. Lindell RM, Hartman TE, Swensen SJ, et al. Fiveyear lung cancer screening experience: $\mathrm{Ct}$ appearance, growth rate, location and histologic features of 61 lung cancers. Radiology 2007:242:555-62.

12. Ashraf $\mathbf{H}$, Dirksen A, Loft $A$, et al. Combined use of positron emission tomography and volume doubling time in lung cancer screening with low-dose CT scanning. Thorax 2011;66:315-19.

13. Silvestri GA, Nietert PJ, Zoller J, et al. Attitudes towards screening for lung cancer among smokers and their non-smoking counterparts. Thorax 2007:62:126-30.

14. Aberle DR, Adams AM, Berg CD, et al. Baseline characteristics of participants in the randomised National Lung Screening Trial. J Nat/ Cancer Inst 2010;102:1771-9.

\title{
Collateral ventilation and selection of techniques for bronchoscopic lung volume reduction
}

\section{Pallav L Shah, ${ }^{1,2,3}$ Duncan M Geddes ${ }^{1}$}

Lung volume reduction can give substantial benefit to selected patients with emphysema. However, the high morbidity associated with surgery has fuelled the development of bronchoscopic lung volume reduction. Investment in research has primarily focused on the development of endobronchial valves. Three large randomised controlled trials with endobronchial valves have only shown marginal clinical benefit overall, although some patients had significant improvement in pulmonary function. ${ }^{1-3}$ Cohort studies have also demonstrated a survival benefit in patients who developed lobar atelectasis. ${ }^{45}$ Collateral ventilation appears to be the key factor that limits the effectiveness

\footnotetext{
${ }^{1}$ Department of Respiratory Medicine, Royal Brompton and Harefield NHS Foundation Trust, London, UK; ${ }^{2}$ Department of Respiratory Medicine, Chelsea and Westminster Hospital, London, UK; ${ }^{3}$ National Heart \&
} Lung Institute, Imperial College, London, UK

Correspondence to Dr Pallav Shah, Royal Brompton Hospital, Sydney Street, London SW3 6NP, UK; pallav.shah@imperial.ac.uk of endobronchial valves. ${ }^{6}$ Support for this theory has been enhanced by subgroup analysis of the Endobronchial Valve for Emphysema Palliation Trial (VENT) study, which has shown the greatest improvements in lung function (17.9\% improvement in forced expiratory volume in $1 \mathrm{~s}$ $\left[\mathrm{FEV}_{1}\right]$ at 12 months) in patients who had evidence of an intact fissure on the treatment side providing the endobronchial valves were correctly positioned. ${ }^{1}$ The absence of any clinical benefit in patients treated with incomplete bilateral lobar occlusion further supports the theory that complete isolation of the lobe is required for blocking devices to be effective. ${ }^{3}$

Spiracles or transthoracic passages were described by the late Peter Macklem as a method for reducing trapped gas in lungs when there is a high degree of collateral ventilation. ${ }^{7}$ This can be achieved in patients with emphysema by creating an artificial passage between the chest wall and emphysematous lungs with a valve that directs the flow of air out of the lung. ${ }^{8}$ However, this approach is not well tolerated by patients. An alternative strategy is to create artificial air passages within the lung and bronchial segments that allow trapped gas to escape. This technique (airway bypass) has the greatest benefit in patients with a high degree of collateral ventilation, but benefits reported so far have been only transient. ${ }^{9}$

The development of bronchoscopic treatments that are independent of collateral ventilation is essential and Ingenito $e t$ al first described the use of a fibrin glue in a sheep model of emphysema to induce lung volume reduction. ${ }^{10}$ This strategy has evolved for human use and Magnussen et al report on the use of a polymeric foam sealant in advanced emphysema. ${ }^{11} \mathrm{~A}$ polymeric solution $(4.5 \mathrm{ml}$ of $2 \%$ aminated polyvinylalcohol in phosphate buffer) is mixed with a cross linker $(0.5 \mathrm{ml}$ of buffered pentane $1-5$ dial). The mixture is then mixed with $15 \mathrm{ml}$ of air to create a foam and the solution is then instilled into the target bronchial segment during flexible bronchoscopy via catheter. The air within the foam is gradually resorbed and the adherent pulmonary tissue in the treatment area also shrinks with the foam. The authors have amalgamated the data from three separate but similar clinical trial protocols and subsequently assessed treatment response according to fissure integrity based on the CT scans. The results for this study are impressive, with improvements in $\mathrm{FEV}_{1}$ of $19 \%$, exercise capacity by $30 \mathrm{~m}$ and quality of life (St George's Respiratory Questionnaire, SGRQ) by about 11 points. Furthermore, the proportion of patients who had a clinically 
significant improvement was $64 \%$ for $\mathrm{FEV}_{1}$ $\left(12 \%\right.$ improvement in $\left.\mathrm{FEV}_{1}\right), 31 \%$ for exercise capacity ( 6 min walk test of more than $54 \mathrm{~m}$ ) and $71 \%$ for SGRQ (reduction by four points). However, the degree of improvement needs to be interpreted with caution as small open-label cohort studies tend to consistently demonstrate a greater degree of benefits than are ultimately observed in large-scale randomised trials. This effect may be exaggerated as the authors have only looked at a subgroup (28 patients who had derivable information on fissure status on CT scans) rather than the whole cohort of 54 patients treated.

This study has not reported on the safety aspects but a previous study of 25 patients suggests an early transient systemic inflammatory response with fevers, flu-like symptoms and chest discomfort. ${ }^{12}$ There were exacerbations of chronic obstructive pulmonary disease (COPD) in eight patients requiring hospitalisation and one needed treatment in an intensive care unit. The event rate may seem high but should be considered in the context of this population of patients who have severe disease, frequent exacerbations and limited treatment options. However, treatment with the polymeric foam sealant is irreversible. It remains in situ in the lung and induces permanent sclerosis. Longer-term effects remain unclear and it should be used with caution in patients with Global Initiative for Chronic Obstructive Lung Disease (GOLD) stage III disease.

Bronchoscopic lung volume reduction should be considered in patients with severe emphysema with evidence of hyperinflation (residual volume $>180 \%$ predicted) who are symptomatic despite maximal medical therapy. Endobronchial valves which are easily removed should be considered initially in patients who have an intact fissure on CT scans or evidence of low collateral ventilation. Patients who have significant collateral ventilation may need to be considered for alternative treatments such as the polymeric foam sealant.

Contributors This editorial was jointly written by PS and DG.

Competing interests PS has been involved in a number of clinical trials on bronchoscopic lung volume reduction and the host centres (Royal Brompton Hospital and the Chelsea \& Westminster Hospital) have been reimbursed for clinical trial expenses. There are no competing interests with respect to the emphysematous lung sealant (AeriSeal®). DM has no competing interests.

Provenance and peer review Not commissioned; internally peer reviewed.

Published Online First 28 February 2012

Thorax 2012;67:285-286.

doi:10.1136/thoraxjnl-2012-201648

\section{REFERENCES}

1. Sciurba FC, Ernst A, Herth FJ, et al; VENT Study Research Group. A randomized study of endobronchial valves for advanced emphysema. N Engl J Med 2010;363:1233-44.

2. Herth FJ, Noppen M, Valipour A, et al. Efficacy predictors of lung volume reduction with Zephyr valves in a European cohort. Eur Respir J Published Online First 26 Jan 2012. doi:10.1183/ 09031936.00161611

3. Ninane V, Geltner C, Bezzi M, et al. Multicentre European study for the treatment of advanced emphysema with bronchial valves. Eur Respir J. In press.

4. Hopkinson NS, Shah PL, Polkey MI. Endobronchial valves for emphysema. $N$ Engl J Med 2011;364:381-2.

5. Hopkinson NS, Kemp SV, Toma TP, et al. Atelectasis and survival after bronchoscopic lung volume reduction for COPD. Eur Respir $J$ 2011;37:1346-51.

6. Cetti EJ, Moore AJ, Geddes DM. Collateral ventilation. Thorax 2006:61:371-3.

7. Macklem PT. Collateral ventilation. N Engl J Med 1978;298:49-50.

8. Moore AJ, Cetti E, Haj-Yahia S, et al. Unilateral extrapulmonary airway bypass in advanced emphysema. Ann Thorac Surg 2010;89:899-906.

9. Shah PL, Slebos DJ, Cardoso PF, et al; EASE Trial Study Group. Bronchoscopic lung-volume reduction with Exhale airway stents for emphysema (EASE trial): randomised, sham-controlled, multicentre trial. Lancet 2011;378:997-1005.

10. Ingenito EP, Reilly JJ, Mentzer SJ, et al. Bronchoscopic volume reduction: a safe and effective alternative to surgical therapy for emphysema. $A m \mathrm{~J}$ Respir Crit Care Med 2001;164:295-301.

11. Magnussen H, Kramer RM, Kirsten AM, et al. Effect of fissure integrity on lung volume reduction using a polymer sealant in advanced emphysema. Thorax 2012:67:302-8

12. Herth FJ, Gompelmann D, Stanzel F, et al. Treatmen of advanced emphysema with emphysematous lung sealant (AeriSeal®). Respiration 2011;82:36-45.

\section{MDR, XDR, TDR tuberculosis: ominous progression}

\section{Zarir F Udwadia}

\begin{abstract}
Any man's death diminishes me because I am involved in mankind, and therefore never send to know for whom the bell tolls; it tolls for thee... (John Donne, Meditation XV11)

The growing TB epidemic is no longer an emergency only for those who care about health, but also for those who care about justice. (PD O Davies)
\end{abstract}

For 2 weeks in January, India coughed and the rest of the world paid attention. Drugresistant tuberculosis (TB), languishing from a decade of neglect by the Indian

Correspondence to Zarir F Udwadia, Hinduja Hospital and Research Center, Mumbai 400020, India; zfu@hindujahospital.com
Revised National Tuberculosis Control Program (RNTCP), was headline news in every Indian newspaper and several international ones as well.

What captured local and international attention was a report documenting the isolation of the first cases of totally drug resistant TB (TDR-TB) from India. ${ }^{1}$ The Indian government's response, after initial denial, swung from the ridiculous to the sublime. The WHO response was far more measured and authoritative. Paul Nunn, coordinator of WHO's STOP TB department in Geneva, described the cases as "a wake up call for countries to accelerate provision of proper care, particularly for multi drug-resistant patients". Within a week WHO had a TDR link on its website with answers to frequently asked questions, was planning a new consensus definition of TDR-TB, and had planned an expert meeting to rethink strategy.

$\mathrm{TB}$ exists on an epic scale in India. It resolutely remains India's biggest public health problem. India bears a disproportionately large burden of the world's TB, one a developing country can ill afford, with an estimated economic loss of US $\$ 43$ billion and 100 million productive days lost annually directly due to this disease. The facts speak for themselves: India is the highest TB burden country in the world with 300 million Indians infected, accounting for $21 \%$ of the global incidence. $^{2}$ It is estimated that TB kills 300000 Indians annually: one death every 2 min, a grim statistic that has changed little over the decades. ${ }^{3}$

The situation is even worse when it comes to multidrug resistant TB (MDRTB). Here again India emerges a global hot spot with the latest WHO anti-TB drug 